\section{Sunbeds: A burning issue needing attention in South Africa}

To the Editor: There is scientific evidence demonstrating an association between sunbed (tanning bed) use and subsequent development of melanoma. ${ }^{[1,2]}$ The risk of melanoma skin cancer for individuals who 'ever used' sunbeds has been reported to increase by $20 \%$, and by $40 \%$ if sunbeds were used before the age of 35 years. ${ }^{[1,2]}$ In South Africa (SA), skin cancer is among the top 10 cancers and causes $\sim 300$ deaths per year. ${ }^{[3]}$ The cost of diagnosis and treatment of skin cancers in SA public and private healthcare settings is estimated at $>$ ZAR90 million per year. ${ }^{[4]}$

Prevalence data from surveys and data from GLOBOCAN were used to estimate that, in 2008, 3438 cases of melanoma could be attributable to sunbed use, most ( $n=2341$ ) occurring among women, in 15 member countries of the European Community (plus three member countries of the European Free Trade Association) ${ }^{[1]}$ While we do not have such figures for SA, we identified one South African who had used a sunbed prior to the development of an invasive amelanotic melanoma on her left leg. Fig. 1 presents a timeline of her sun exposure history and melanoma diagnosis and treatment up to 2 October 2018.

The International Agency for Research on Cancer classified ultraviolet (UV)-emitting tanning devices, i.e. sunbeds, as carcinogenic in 2009 and concluded that there is no safe limit for UV from such devices. ${ }^{[5]}$ The World Health Organization ${ }^{[6]}$ stated that countries need to educate the public about the health risks of UV exposure from sunbeds and apply regulations to restrict their use, ${ }^{[7]}$ such as banning use of sunbeds by people with sensitive skin, banning unsupervised operations, banning hire/sale of sunbeds, enforcing registration of sunbeds and sunbed premises, periodic inspections of sunbed premises, and fines for any infringements of proclaimed restrictions. Recent legislation in several countries around the world bans commercial sunbeds (Appendix 1; available in the online version of this article at https://doi.org/10.7196/SAMJ.2018.v108i12.13715). ${ }^{[8]}$

In SA, sunbeds are widely available ${ }^{[9]}$ for use in beauty salons, fitness gyms and hair salons, and for sale, both new and second hand. We postulate that trying to regulate sunbed operators in SA will be challenging. There is lack of compliance of sunbed operators with the South African Consumer Protection Act No. 68 of $2008^{[10]}$ (that restricts false advertising) to not overstate the perceived 'benefits' of sunbed use including that 'sunbeds condition skin before going outdoors in summer'. The cost of regulation and compliance is prohibitive. Local authorities would be mandated to oversee sunbed regulation, and their scope of work is already burdensome. Sunbeds are geographically dispersed throughout the country, ${ }^{[9]}$ so ongoing efforts to ensure compliance would be costly. Second-hand, ex-commercial sunbeds may be disposed of in the second-hand market, possibly to private residences, making regulation challenging. In some countries that have banned sunbeds, sunbeds were removed from premises, and sunbed operators were compensated.

A ban on sunbeds is probably the best way forward for SA, although it will not be a simple process. We could also consider additional taxes for tanning sessions, such as those placed on tobacco and recently sugar, to drive down demand, as an example of possible regulatory action by government, but this would still require compliance monitoring. Embarking on a nationwide education campaign in SA to educate the public on risks associated with using sunbeds will require prolonged and ongoing commitment by the National Department of Health, the Cancer Association of South Africa and others working for primary and secondary prevention of skin cancer.

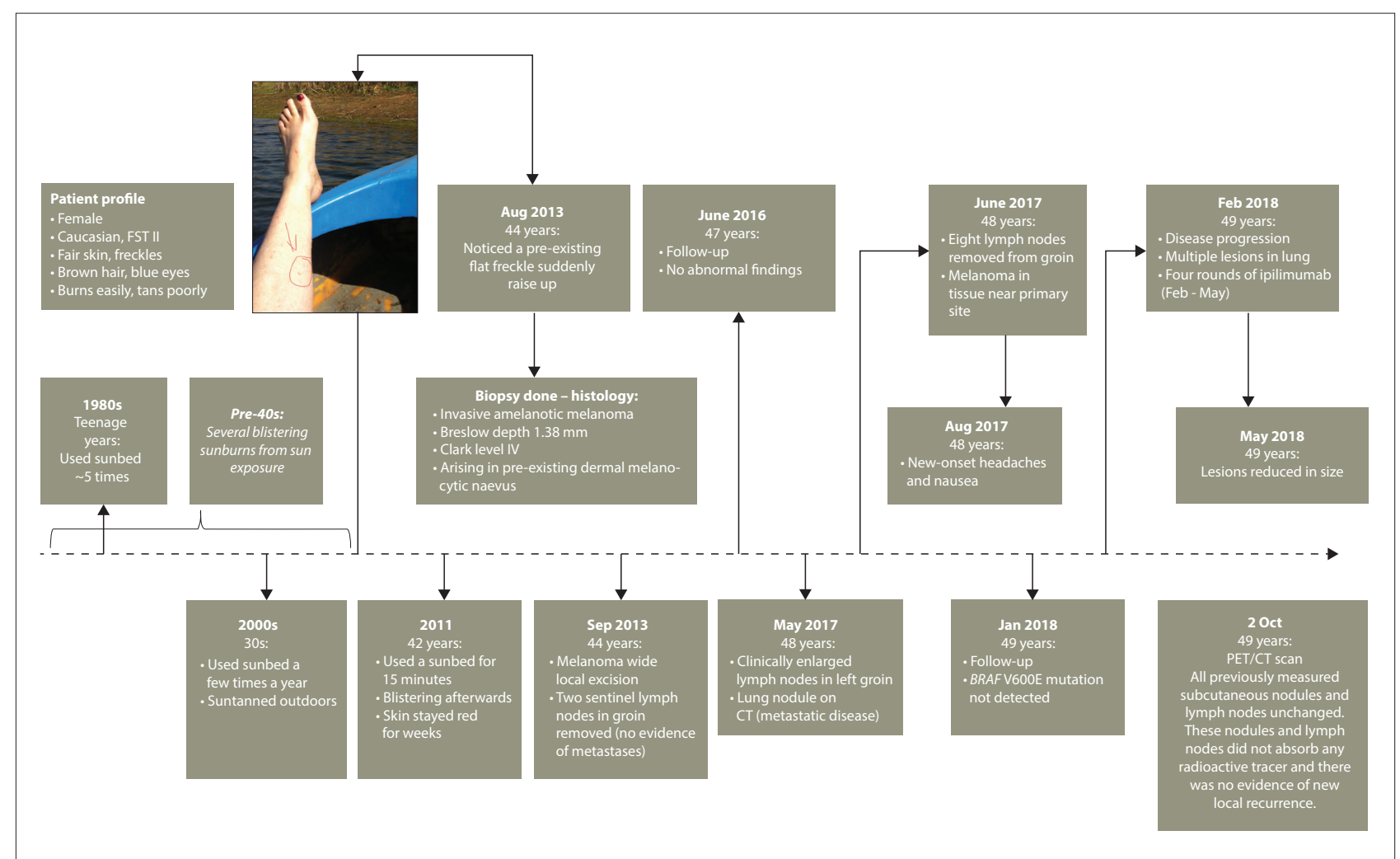

Fig. 1. Timeline of a melanoma patient who used a sunbed during her teenage years and again during her 30 s, and developed an invasive amelanotic melanoma 2 years after experiencing a bad sunburn from a sunbed. While sunbed use is only one of many risk factors, it is a modifiable risk factor, since one can choose not to use a sunbed. (FST II = Fitzpatrick skin type II; CT = computed tomography; PET = positron emission tomography.) 


\section{Y Wright}

Environment and Health Research Unit, South African Medical Research Council; and Department of Geography, Geoinformatics and Meteorology, Faculty of Natural and Agricultural Sciences, University of Pretoria, South Africa

cwright@mrc.ac.za

\section{Z Kunene}

Environment and Health Research Unit, South African Medical Research Council, Johannesburg, South Africa

\section{W Visser}

Division of Dermatology, Department of Medicine, Faculty of Medicine and Health Sciences, Stellenbosch University and Tygerberg Academic Hospital, Cape Town, South Africa

\section{A Mathee}

Environment and Health Research Unit, South African Medical Research Council, Johannesburg, South Africa; Environmental Health Department, Faculty of Health Sciences, University of Johannesburg, South Africa; and School of Public Health, Faculty of Health Science, University of the Witwatersrand, Johannesburg, South Africa
1. Boniol M, Autier P, Boyle P, Gandini S. Cutaneous melanoma attributable to sunbed use: Systematic review and meta-analysis. BMJ 2012;345:e4757. https://doi.org/10.1136/bmj.e4757

2. Wehner MR, Shive ML, Chren M-M, Han J, Qureshi AA, Linos E. Indoor tanning and nonmelanoma skin cancer: Systematic review and meta-analysis. BMJ 2012;345:e5909. https://doi.org/10.1136/ bmj.e5909

3. Norval M, Kellet $\mathrm{P}$, Wright $\mathrm{CY}$. The incidence and body site of skin cancers in the population groups of South Africa. Photoderm Photoimmunol Photomed 2014;30(5):262-265. https://doi.org/10.1111/ phpp. 12106

4. Gordon L, Elliott T, Wright CY, Deghaye N, Visser W. Modelling the healthcare costs of skin cancer in South Africa. BMC Public Health 2016;16:113. https://doi.org/10.1186/s12913-016-1364-z

5. International Agency for Research on Cancer. Sunbeds and UV radiation. https://www.iarc.fr/en/ media-centre/iarcnews/2009/sunbeds_uvradiation.php (accessed 8 January 2018).

6. World Health Organization. Artificial tanning devices: Public health interventions to manage sunbeds. http://www.who.int/uv/publications/artificial-tanning-devices/en/ (accessed 8 January 2018).

7. World Health Organization. Artificial tanning sunbeds: Risks and guidance. http://www.who.int/uv/ publications/sunbedpubl/en/ (accessed 8 January 2018).

8. Global Health Observatory Data Repository of the World Health Organization. http://apps.who.int/ gho/data/node.main.SUNBEDSEXISTENCE?lang=en (accessed 13 November 2018).

9. Wright CY, Albers PN, Reeder AI, Mathee A. Sunbeds and skin cancer risk: Quantifying a baseline estimate of sunbed facilities in South Africa prior to implementation of sunbed regulations. Pan Afr Med J 2017;26:188. https://doi.org/10.11604/pamj.2017.26.188.10176

10. South Africa. Consumer Protection Act No. 68 of 2008. https://www.gov.za/sites/default/files/ 32186_467_0.pdf (accessed 9 October 2018).

S Afr Med J 2018;108(12):1004-1006. DOI:10.7196/SAMJ.2018.v108i12.13715 


\section{Appendix 1}

Countries that have banned sunbeds (World Health Organization ${ }^{[8]}$ )

\begin{tabular}{|c|c|c|c|}
\hline Country & $\begin{array}{l}\text { Existence of national } \\
\text { regulation }\end{array}$ & $\begin{array}{l}\text { Year of national implementation } \\
\text { of regulation }\end{array}$ & $\begin{array}{l}\text { Existence of subnational } \\
\text { regulation }\end{array}$ \\
\hline Argentina & No & & Yes \\
\hline Australia & No & & Yes \\
\hline Austria & Yes & 1995 & No \\
\hline Bahrain & No & & No \\
\hline Belgium & Yes & 2017 & No \\
\hline Bolivia & No & & No \\
\hline Brazil & Yes & 2009 & No \\
\hline Bulgaria & No & & No \\
\hline Canada & Yes & 2014 & Yes \\
\hline Chile & Yes & 2013 & No \\
\hline China & No & & No \\
\hline Colombia & Yes & 2005 & No \\
\hline Cuba & No & & No \\
\hline Cyprus & No & & No \\
\hline Denmark & Yes & 2014 & No \\
\hline Egypt & No & & No \\
\hline Finland & Yes & 2012 & No \\
\hline France & Yes & 2014 & No \\
\hline Germany & Yes & 2012 & No \\
\hline Greece & No & & No \\
\hline Iceland & Yes & 2003 & No \\
\hline Iran & No & & No \\
\hline Iraq & No & & No \\
\hline Ireland & Yes & 2015 & Yes \\
\hline Israel & Yes & 2014 & No \\
\hline Italy & Yes & 2011 & Yes \\
\hline Latvia & Yes & 2010 & No \\
\hline Luxembourg & No & & No \\
\hline Malaysia & No & & No \\
\hline Morocco & No & & No \\
\hline Netherlands & Yes & 2015 & No \\
\hline New Zealand & Yes & 2017 & Yes \\
\hline Norway & Yes & 2016 & No \\
\hline Philippines & No & & No \\
\hline Qatar & No & & No \\
\hline Saudi Arabia & No & & No \\
\hline Slovakia & Yes & 2014 & No \\
\hline Slovenia & Yes & 2009 & No \\
\hline Spain & Yes & 2002 & Yes \\
\hline Sweden & Yes & 2012 & No \\
\hline Switzerland & Yes & 2013 & Yes \\
\hline United Arab Emirates & No & & Yes \\
\hline UK & No & & Yes \\
\hline USA & Yes & & Yes \\
\hline
\end{tabular}

